\title{
Enchytraeids and Nematophagous Fungi in Tomato Fields and Vineyards
}

\author{
B. A. Jaffee
}

Department of Nematology, University of California at Davis, One Shields Avenue, Davis 95616-8668. Accepted for publication 25 January 1999.

ABSTRACT

\begin{abstract}
Jaffee, B. A. 1999. Enchytraeids and nematophagous fungi in tomato fields and vineyards. Phytopathology 89:398-406.

I tested the hypothesis that exclusion of enchytraeids and microarthropods in agricultural fields improves establishment of two nematophagous fungi. Soil was collected from three tomato fields and two vineyards and either heat-treated $\left(2 \mathrm{~h}\right.$ at $\left.60^{\circ} \mathrm{C}\right)$ or not. Alginate pellets containing hyphae of the fungi Hirsutella rhossiliensis or Monacrosporium gephyropagum were added to the soil, which was packed into cages (PVC pipe, $80-\mathrm{cm}^{3}$ volume) sealed with fine $(20 \mu \mathrm{m})$ or coarse $(480 \mu \mathrm{m})$ mesh. Cages were buried $22 \mathrm{~cm}$ deep in the same fields from which the soil had been collected.
\end{abstract}

After 7 to 50 days, the cages were recovered and fungi and fauna quantified. Fine mesh largely excluded enchytraeids, collembolans, and mites but rarely affected fungus numbers. In contrast, heat treatment of soil rarely affected enchytraeids, collembolans, or mites but frequently increased fungus numbers, regardless of mesh size. The data are inconsistent with the initial hypothesis but are consistent with the idea that organisms narrower than $20 \mu \mathrm{m}$ interfere with fungal growth from the pellets.

Additional keywords: bacterivorous nematodes, biological control, fungivorous nematodes, omnivorous nematodes, plant-parasitic nematodes.
In some ways, adding nematophagous fungi to soil seems foolish. On the one hand, these fungi are already there, albeit in numbers usually too small to control plant-parasitic nematodes (41). On the other hand, the added fungi are likely to be eliminated by many resident antagonists (9). Nevertheless, adding fungus inoculum to soil is a direct and rapid approach to nematode control, and some researchers find this approach worth investigating $(4,16,33,42)$.

Among the kinds of inoculum that can be added to soil, the fungus-parasitized nematode has some desirable characteristics. First, the parasitized host often acts as a focus for the production of infective propagules and is an important stage in the life history of many fungi that attack soil nematodes and insects $(11,13,18,21,24$, 36). Second, fungi growing from their hosts presumably experience minimal competition from other fungi and bacteria, because growth from the host does not require capture of new resource, only conversion of captured resource into new structures. For example, the endoparasitic fungus Hirsutella rhossiliensis first converts the nematode host into a bag of assimilative hyphae and then converts the hyphae into external conidia that adhere to and initiate infection of nematodes (21). Similarly, the nematode-trapping fungus Monacrosporium gephyropagum first converts the trapped nematode into assimilative hyphae internal to the host and then into external, adhesive branches (18).

Although fungus-parasitized nematodes substantially suppressed target nematodes in the laboratory $(14,24,43,44)$, treatment of large volumes of soil in the field would not be practical; the inoculum could not be produced and stored in sufficient quantities. Lackey et al. (28), therefore, developed a substitute consisting of assimilative hyphae embedded in alginate pellets. Like the fungus-parasitized nematode, the pellet acts as a focus for production of infective propagules.

Pelletized hyphae of $H$. rhossiliensis and $M$. gephyropagum performed well in laboratory microcosms $(14,44)$ but less well in field microplots (16). Based on field observations and field exclosure experiments, Jaffee et al. (19) inferred that the efficacy of both fungi

Corresponding author: B. A. Jaffee; E-mail address: bajaffee@ucdavis.edu

Publication no. P-1999-0301-01R

(C) 1999 The American Phytopathological Society was reduced by enchytraeid worms. Indeed, enchytraeid reproduction increased dramatically when pelletized hyphae were added to soil (17). Fungivory by enchytraeids seemed especially interesting, in part because fungivory has been infrequently considered in the plant pathology literature $(3,12,23,39,40)$. Moreover, enchytraeids, which are closely related to earthworms, are apparently quite common (5) but seldom studied in the United States (45).

Data implicating enchytraeids in the population dynamics of nematophagous fungi were obtained from only one soil, a very porous loamy sand located on the campus of the University of California at Davis (19). In the current study, I determined whether enchytraeids and certain other soil fauna affected pelletized $H$. rhossiliensis and $M$. gephyropagum in several commercial tomato fields and vineyards in California.

\section{MATERIALS AND METHODS}

Pellets. $M$. gephyropagum (ARSEF 3348, M. cionopagum) and H. rhossiliensis (IMI 265748) were cultured on quarter-strength cornmeal agar (CMA/4). Hyphae were grown in shake culture, rinsed free of media, macerated, embedded in alginate, coated in sand, and dried as described before $(16,28)$. M. gephyropagum pellets were heavier (1.8 versus $1.1 \mathrm{mg}$ ) and larger (2.2 versus $1.9 \mathrm{~mm})$ than those of $H$. rhossiliensis. The approximate mass of dry hyphae per pellet, based on the number of pellets produced per unit of dry hyphae, was $0.7 \mathrm{mg}$ for $M$. gephyropagum and $0.3 \mathrm{mg}$ for $H$. rhossiliensis.

Pellets were stored in glass vials at $5^{\circ} \mathrm{C}$ for less than 16 days in all but one experiment (pellets were stored for 50 days in the first experiment with $H$. rhossiliensis at site 3 ). They were added at the rate of 0.5 pellet of $M$. gephyropagum or 1.0 pellet of $H$. rhossiliensis per $\mathrm{cm}^{3}$ of soil. In previous studies, this quantity of $M$. gephyropagum pellets produced relatively large numbers of $M$. gephyropagum propagules and substantially suppressed nematodes (16). I used a greater number of $H$. rhossiliensis than of $M$. gephyropagum pellets, because no activity of $H$. rhossiliensis could be detected when it was added in smaller quantities in earlier studies (16). Moreover, the mass of pellets added was similar ( $0.9 \mathrm{~g} /$ /iter of soil for $M$. gephyropagum and $1.1 \mathrm{~g} /$ liter of soil for $H$. rhossiliensis). 
Soil and sites. Sandy soils were used because they tend to have nematode problems, are relatively easy to work with, and may support rapid movement of enchytraeids and other fungivores to pellets. Three tomato fields (sites 1 to 3 ) in Yolo County were selected in 1997. These sites were sandier than many others in Yolo County but were less sandy than our campus plots (Table 1). In 1998, sites 4 and 5 (vineyards in San Joaquin County) were included because they were sandier than sites 1 to 3 . Soil textural and other characteristics (Table 1) were determined from a composite, non-heat-treated sample by the Division of Agriculture and Natural Resources (DANR) Analytical Laboratory (University of California, Davis).

Within 15 days before starting an experiment in a site, about 6 liters of soil ( 5 to $25 \mathrm{~cm}$ deep) was collected from the site and kept at $10^{\circ} \mathrm{C}$ unless otherwise noted. The soil was mixed, and clods larger than $4 \mathrm{~mm}$ were broken by hand. To reduce biotic antagonism of $M$. gephyropagum and $H$. rhossiliensis and especially to provide an environment initially free of enchytraeids, half the soil was heated to $60^{\circ} \mathrm{C}$ for $2 \mathrm{~h}$. The heat eliminates nematodes, enchytraeids, arthropods, and nematode-trapping fungi and reduces numbers of other microorganisms but does not sterilize the soil (19). After heat treatment, the soil was exposed to the air on a laboratory bench for 2 to $4 \mathrm{~h}$ to allow potentially toxic volatiles to escape and also to reduce the soil moisture content. Reducing the moisture content was necessary to avoid excessive compaction of the soil when it was placed in soil cages. The non-heat-treated soil was exposed to air for about $2 \mathrm{~h}$ so that its moisture content was nearly equivalent to that of the heat-treated soil. Minor differences in water content between heat-treated and non-heat-treated soil were eliminated by adding small volumes of distilled water to the heat-treated soil.

Cages. To separate the effects of large and small organisms on $M$. gephyropagum and $H$. rhossiliensis, cages were used (19). A cage consisted of two sections of 3.9-cm-diameter PVC pipe, each of which was $3 \mathrm{~cm}$ long and covered on one end with nylon mesh. The mesh was either coarse or fine (480- or 20- $\mu$ m-diameter openings). After pellets were mixed into soil, the soil was packed into each section and the two sections were joined with 'pipe wrap' tape. Thus, each cage was $6.0 \mathrm{~cm}$ long, $80 \mathrm{~cm}^{3}$ in volume, and had either coarse or fine mesh at both ends. The initial soil moisture content in the cage was between 7.5 and $11.1 \%$ and was typically about 2 to $3 \%$ drier than the soil in the field at the start of an experiment. After cages were packed with soil, they were sealed in plastic bags and placed in an ice chest. Within $2 \mathrm{~h}$ of packing, cages were buried in the field. The soil in the cage always had been collected from the same site where the cage was buried.

Experiments. The experimental design was a $2 \times 2$ factorial with heat treatment $( \pm)$ and mesh (coarse or fine) as the main factors. Cages were placed in four blocks. In the tomato fields (sites 1 to 3), adjacent blocks were $10 \mathrm{~m}$ apart down a single row and were at least $15 \mathrm{~m}$ from the edge of the field. Cages were oriented vertically (mesh at top and bottom) and buried between the center and the edge of the planting bed. Although the effect of vertical versus horizontal orientation is unknown, in previous experiments large numbers of enchytraeids, and sometimes mites and collem- bolans, entered vertically oriented cages (19). The top of each cage was $19 \mathrm{~cm}$ from the soil surface. This depth was $10 \mathrm{~cm}$ greater than in a previous study (19), because I was concerned that cultivation would damage the cages. The cages were placed in a line parallel to the furrow with about $2 \mathrm{~cm}$ between adjacent cages. In the first experiment at site 3 , planting beds and furrows were not present and cages were buried in a line, with $10 \mathrm{~m}$ between blocks. Blocks of repeated experiments at each site were located in the same general area but not in the exact location of previous blocks. As cages were buried, $500 \mathrm{~cm}^{3}$ of soil was collected from each block and was used to estimate numbers of enchytraeids at time 0 in soil surrounding the cages.

At the vineyards (sites 4 and 5), adjacent blocks were 2 to $4 \mathrm{~m}$ apart down a single row and at least $10 \mathrm{~m}$ from the edge of the field. Blocks were located in the center of the vine row, one block between adjacent vines. Cages were buried at the same depth and with the same orientation as in tomato fields. Cover crops were grown between the vine rows in both vineyards during the winter and spring of 1998.

A temperature recorder (Hobo-Temp model; Onset Computer Corporation, Pocasset, MA) was buried with the cages in two of the four blocks of each experiment, and temperature was recorded hourly. Mean temperature and accumulated heat units (degree days, base $10^{\circ} \mathrm{C}$ ) were determined. Information on irrigation was obtained by observing the field and talking with the growers. Rainfall data were obtained from the University of California Integrated Pest Management Data Base (University of California, Davis).

Timing of experiments. Although sampling repeatedly over time would have been useful, many experiments were conducted with one sampling time per experiment to increase the range of sites and environmental conditions. Experiments at sites 1 and 2 included only $M$. gephyropagum, those at site 3 included only $H$. rhossiliensis, and those at sites 4 and 5 included both fungi. For each combination of fungus and site, three experiments were performed: 7 in the spring of 1997 and 14 in the spring of 1998. At site 1 ( $M$. gephyropagum only), the first experiment was started on 26 February 1997, 3 days after seeding of tomato. The second and third experiments at site 1 were started in April and May 1997. At site 2 (M. gephyropagum only), the first experiment was started on 26 February 1997, and tomatoes were transplanted on 22 April 1997. The second and third experiments at site 2 were started in April and May 1997 . The primary crop at site 3 (H. rhossiliensis only) was tomato, but wheat was growing on 28 February 1997, when the first experiment was started. The second and third experiments at site 3 were started on 7 March and 16 March 1998 and were completed several days before tomato seeds were planted. Both fungi were tested independently at sites 4 and 5, where grape vines had been planted in 1979 and 1967, respectively. The first experiments were started in February and March 1998, and the third experiments were completed in May and June 1998.

Lengths of all experiments are provided below. The decision to terminate an experiment was based on fungus biology and soil water content. In soil at $20^{\circ} \mathrm{C}$, numbers of $M$. gephyropagum tend to rapidly increase and then rapidly decrease, whereas $H$. rhossiliensis

TABLE 1. Physical characteristics of soils collected from six field sites

\begin{tabular}{|c|c|c|c|c|c|c|c|c|c|c|c|c|c|}
\hline \multirow[b]{2}{*}{ Site } & \multirow[b]{2}{*}{ Crop } & \multirow{2}{*}{$\begin{array}{c}\text { Sand } \\
(\%)\end{array}$} & \multirow{2}{*}{$\begin{array}{l}\text { Silt } \\
(\%)\end{array}$} & \multirow{2}{*}{$\begin{array}{l}\text { Clay } \\
(\%)\end{array}$} & \multirow[b]{2}{*}{$\mathrm{pH}^{\mathrm{x}}$} & \multirow{2}{*}{$\begin{array}{c}\text { Organic matter } \\
(\%)\end{array}$} & \multirow{2}{*}{$\begin{array}{c}\text { Bulk } \\
\text { density }\end{array}$} & \multicolumn{6}{|c|}{$\%$ Water at indicated water potential $(-\mathrm{kPa})^{\mathrm{y}}$} \\
\hline & & & & & & & & 0 & 10 & 30 & 100 & 500 & 1,500 \\
\hline 1 & Tomato & 59 & 28 & 13 & 7.2 & 0.8 & 1.29 & 44.5 & 18.9 & 15.8 & 10.7 & 9.0 & 8.9 \\
\hline 2 & Tomato & 53 & 32 & 15 & 7.3 & 1.2 & 1.29 & 47.4 & 20.8 & 13.3 & 11.1 & 9.3 & 9.4 \\
\hline 3 & Wheat/tomato & 71 & 19 & 10 & 7.0 & 1.0 & 1.43 & 39.4 & 14.6 & 9.9 & 8.8 & 6.7 & 7.0 \\
\hline 4 & Grape & 81 & 15 & 4 & 7.0 & 0.4 & 1.49 & 31.2 & 8.7 & 6.5 & 4.6 & 3.6 & 3.5 \\
\hline 5 & Grape & 81 & 15 & 4 & 5.1 & 0.7 & 1.51 & 32.2 & 10.1 & 7.0 & 5.7 & 4.1 & 4.0 \\
\hline Campus $^{\mathrm{z}}$ & Tomato/lettuce & 86 & 11 & 4 & 7.2 & 0.4 & 1.43 & 32.7 & 7.4 & 5.6 & 4.6 & 3.9 & 3.6 \\
\hline
\end{tabular}

${ }^{x}$ Determined from a water-saturated paste.

y Moisture release data were obtained with a tension plate device (29).

${ }^{\mathrm{z}}$ Data for the campus site, from Jaffee et al. (19), are presented for comparison. 
numbers increase and decrease more slowly (15). I planned to collect $M$. gephyropagum cages from the field after about 140 degree days $\left(14\right.$ days at $20^{\circ} \mathrm{C}$ ) and $\mathrm{H}$. rhossiliensis cages after about 210 degree days $\left(21\right.$ days at $\left.20^{\circ} \mathrm{C}\right)$. However, wet soil in cages could not be mixed, so experiments sometimes were ended early to recover cages before an irrigation/rain or ended late to allow sufficient time for drainage after an irrigation/rain. Once recovered from the soil, cages were sealed in plastic bags and kept at $10^{\circ} \mathrm{C}$ for 18 to $50 \mathrm{~h}$ before all processing was completed.

Quantification of M. gephyropagum. Soil from cages containing M. gephyropagum pellets was placed in a plastic bag and mixed. A subsample (20 g of moist soil per cage) was placed in a $125-\mathrm{ml}$ flask, the volume was increased to $50 \mathrm{ml}$ with sterile distilled water, the suspension was shaken, and a 10-fold dilution series was prepared. From each of four dilutions, one $0.1-\mathrm{ml}$ aliquot was placed on each of five CMA/4 plates to which bait nematodes were added $(17,19)$. The surface of the agar was periodically examined for 3 weeks, and the numbers of fungi, by species, per gram of dry soil were estimated using most probable number procedures (27). The percentage of water in the soil ( $\mathrm{g}$ of water per $100 \mathrm{~g}$ of dry soil) was determined from a $15-\mathrm{g}$ subsample. The remaining soil was used to quantify enchytraeids, nematodes, and arthropods.

Quantification of $\boldsymbol{H}$. rhossiliensis. Unlike M. gephyropagum, H. rhossiliensis cannot be detected by soil dilution and plating (15) and a bioassay for conidia on conidiophores was used instead. The bioassay requires that soil not be mixed, because mixing removes conidia from conidiophores and prevents their detection (32). To perform this assay, the sections of each cage were carefully separated. The top section was used to quantify enchytraeids, arthropods, and water content, and the bottom was used to quantify $H$. rhossiliensis and nematodes. Assay nematodes (3,000 second-stage juveniles of Heterodera schachtii) were added to the surface of the soil of each bottom section (19); the nematodes were added in $1.0 \mathrm{ml}$ (if the soil was relatively dry) or $0.5 \mathrm{ml}$ (if the soil was relatively moist) of $4 \mathrm{mM} \mathrm{KCl}$, but the volume was always constant within an experiment. The bottom sections were then sealed in plastic bags. After 2.5 days at $20^{\circ} \mathrm{C}$, nematodes were extracted from the soil (and also from rinse water from the plastic bag, in case nematodes had moved out of the soil) by wet sieving and centrifugation (25). The nematode suspension was reduced to $10 \mathrm{ml}$, and $1 \mathrm{ml}$ was examined at $\times 140$ magnification. Assay nematodes were readily recognized because Heterodera schachtii does not occur naturally in any of the fields; those with and without adhering conidia of $H$. rhossiliensis were counted. The 2.5 days of incubation were sufficient for assay nematodes to acquire conidia but not sufficient for $H$. rhossiliensis to degrade assay nematodes or to sporulate from assay nematodes. The percentage of assay nematodes with at least one adhering conidium of $H$. rhossiliensis was determined. Other nematodes in each sample were counted by trophic group.

Resident fungi. Heat treatment of soil kills both $H$. rhossiliensis and $M$. gephyropagum; therefore, the comparison of fungus numbers in heat-treated versus non-heat-treated soil would be biased if these fungi occurred naturally (resided) in the nonheated soil. Moreover, adding a particular fungus to soil might be more successful if that fungus was resident, i.e., if the fungus was adapted to the soil. To account for resident populations of the fungi, additional cages without pellets were included in the experiments, but this was not done unless the fungi were found to be resident in the soil.

M. gephyropagum was not detected in preliminary soil samples from any site; therefore, cages without $M$. gephyropagum pellets were not included in any experiment. Nevertheless, the absence/presence of resident $M$. gephyropagum was always confirmed as follows. For each experiment with $M$. gephyropagum, five sprinkle plates ( $2 \mathrm{~g}$ of non-heat-treated soil per plate) were prepared from one com-
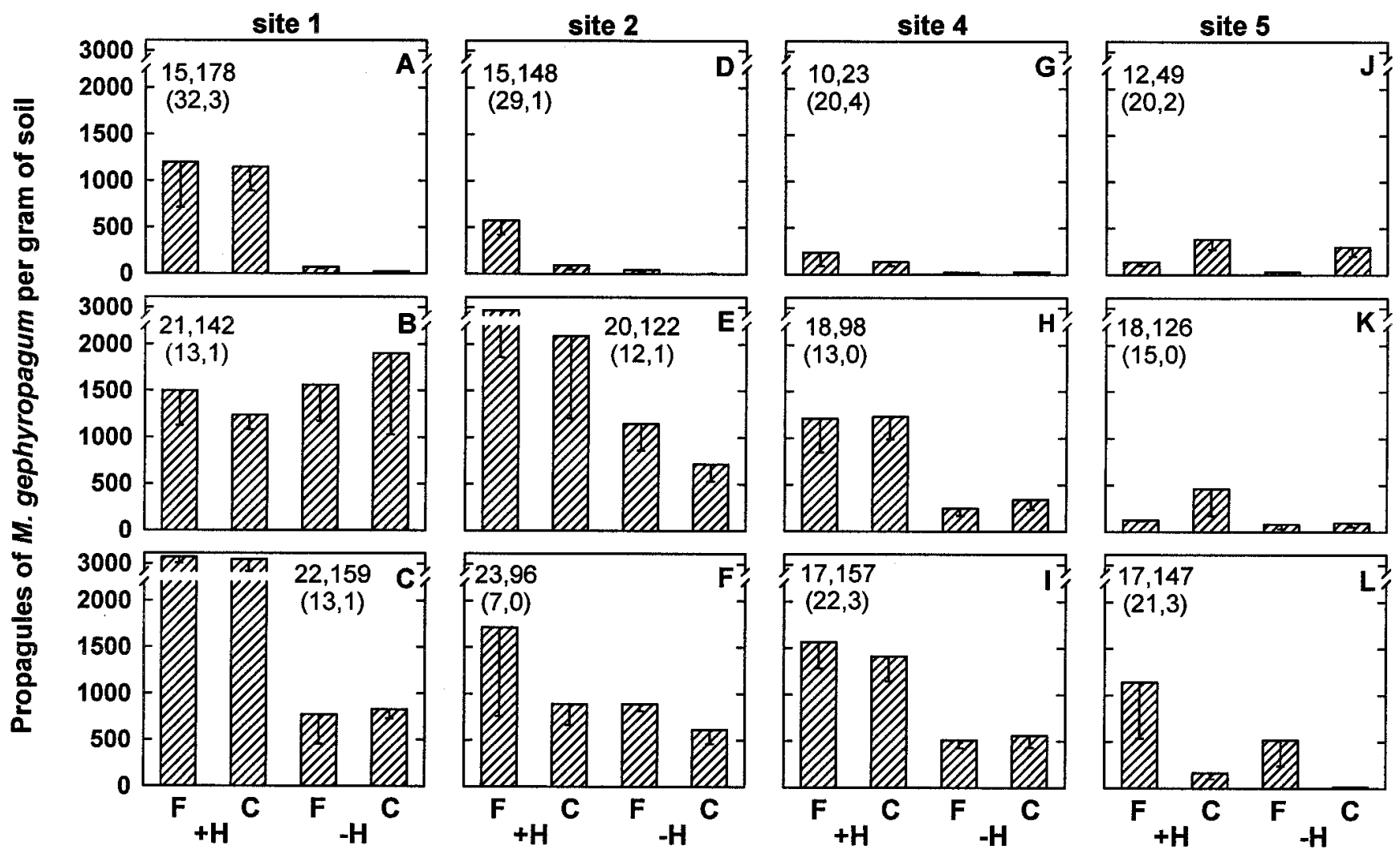

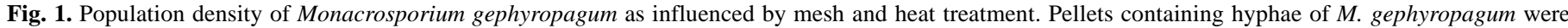

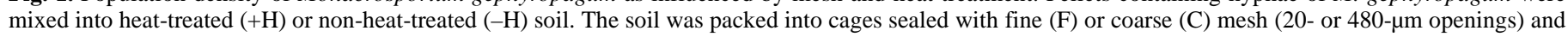

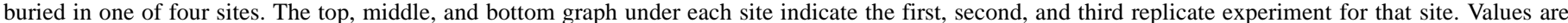

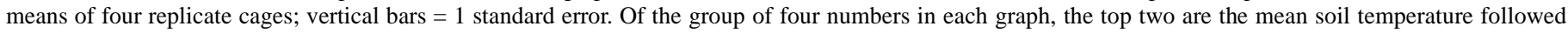

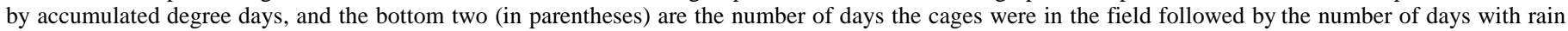
$(>5 \mathrm{~mm})$ or irrigation. 
posite non-heat-treated soil sample. The surface of the agar was periodically examined for 3 weeks. This method detects smaller numbers of $M$. gephyropagum than does soil dilution (20).

Because small numbers of $H$. rhossiliensis-parasitized nematodes were detected in preliminary samples from sites 4 and 5 (but not from site 3), additional cages containing non-heat-treated soil without pellets were included in experiments involving $H$. rhossiliensis pellets at sites 4 and 5. There were eight replicate cages without pellets (four with coarse and four with fine mesh) for each experiment, and these cages were buried, recovered, and processed along with the other cages. To confirm that soil from site 3 did not contain $H$. rhossiliensis, four cage sections containing non-heattreated soil but no pellets were placed in a moist chamber at $20^{\circ} \mathrm{C}$ at the start of each experiment at site 3 . After 2 to 3 weeks, these sections were assayed for $H$. rhossiliensis as described previously in this paper.

Quantification of enchytraeids, nematodes, and arthropods. Enchytraeids were quantified by placing 2.0 and $0.2 \mathrm{~g}$ of moist soil onto each of five replicate CMA/4 plates. After 12 days at $22 \pm 2{ }^{\circ} \mathrm{C}$, each of the 10 plates per sample was assessed for the presence/absence of enchytraeids, and the population density in the sample was estimated using most probable number procedures $(19,27)$. Enchytraeids are difficult to identify, even to genus $(38,45)$. Representative specimens from sites 1 to 3 were sent to W. Didden (Department of Terrestrial Ecology and Nature Conservation, Agricultural University, Wageningen, the Netherlands) for identification to genus. No additional identifications were made. Earthworms may suppress soil fungi (40), but the coarse and fine mesh excluded virtually all earthworms and other macrofauna (data not shown).

Fungivorous nematodes were counted because of their obvious potential to suppress nematophagous fungi. Similarly, omnivorous and bacterial-feeding nematodes were counted because large numbers of these nematodes were previously associated with poor establishment of both fungi (19). In experiments with $M$. gephyropagum, nematodes were extracted from $15 \mathrm{~g}$ of moist soil per cage by wet screening and centrifugation (25). Nematodes were counted by trophic group.

Collembolans and mites were counted because many species are fungivorous (3). Arthropods were extracted from $15 \mathrm{~g}$ of moist soil per cage in Berlese-Tullgren funnels and identified as collembolans, mites, or other arthropods (19).

Statistical analysis. SAS release 6.12 (SAS Institute Inc., Cary, NC) was used throughout. Before analysis, all data, other than percentages, were log-transformed. Because the percentage data from the $H$. rhossiliensis bioassay were sometimes near 100 or 0 , a logit transformation (log [number of assay nematodes with conidia +1 ]/ [number of nematodes without conidia +1 ]) was used. To determine whether numbers of $M$. gephyropagum or percentage of assay nematodes with $H$. rhossiliensis conidia were affected by independent variables (block, soil treatment, mesh, site, experiment within site, block within site, and various interactions), a factorial analysis (separately for each fungus) was performed across sites and within sites. However, the interactions of site $\times$ mesh and mesh $\times$ experiment (within site) were significant. Main effects also could not be examined within a site because of significant experiment $\times$ mesh and experiment $\times$ heat treatment of soil interactions. Therefore, a separate analysis of variance was performed for each experiment, in which the independent variables were block, heat treatment of soil $( \pm)$, mesh (coarse/fine), and the interaction of soil $\times$ mesh.

To determine whether numbers of $H$. rhossiliensis or M. gephyropagum were statistically related to numbers of fauna or soil water content, a series of linear regressions was performed for each combination of fungus and site. All independent variables were initially included in the model statement, but comparison of type I and type III statistics indicated a high degree of confounding among the independent variables (data not shown). Multiple regression was then performed using a consistent subset of independent variables. Selection of a common subset of independent variables for each fungus was necessary, because coefficients would not be comparable among sites if different independent variables were used in the multiple regression model statements. Selection of the common independent variables for the multiple regressions was based on stepwise regression analyses. Although the stepwise algorithm sometimes included independent variables with $P$ values $>0.05$, I only used models with $P \leq 0.05$ for all independent variables. Because the regression models were multiplicative, initial coefficient values were 'exponentiated' (exponentiated coefficient $=e^{\text {initial coefficient }}$ ) to

TABLE 2. Summary of analyses of variance describing how mesh and heat treatment of soil affected numbers of Monacrosporium gephyropagum and Hirsutella rhossiliensis, numbers of other organisms, and soil water content ${ }^{\mathrm{y}}$

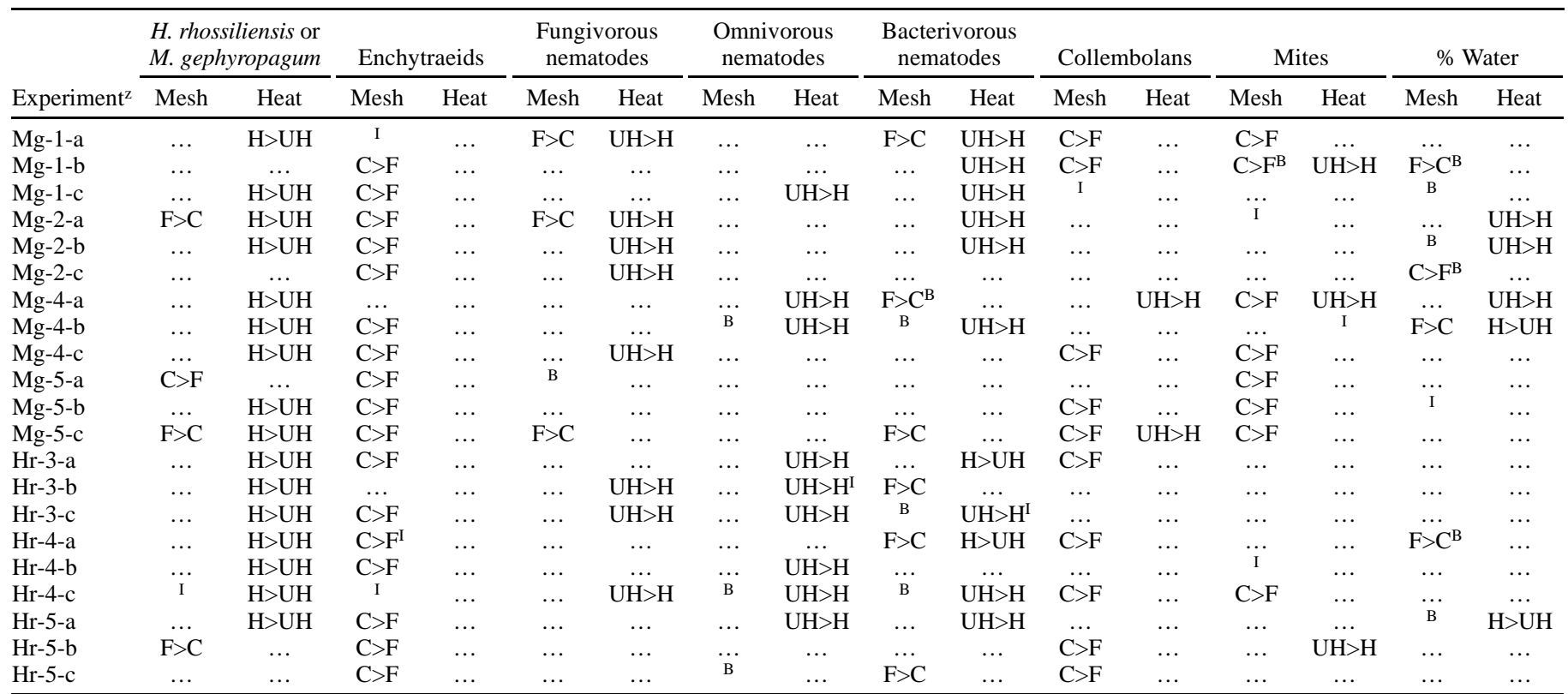

${ }^{y}$ Mesh was either fine $(\mathrm{F})$ or coarse $(\mathrm{C})$, and soil was either heat treated $(\mathrm{H})$ or not $(\mathrm{UH})$. In addition to mesh and heat treatment, independent variables included block and the interaction of mesh $\times$ heat treatment. The sign $(>)$ indicates a significant $(P \leq 0.05)$ main effect and its direction. Superscripts B and I indicate statistical significance for block or the interaction of mesh $\times$ heat treatment, respectively. ... indicates lack of statistical significance.

${ }^{z}$ The first two letters are abbreviations for the fungi, the number indicates the site, and the letters $\mathrm{a}, \mathrm{b}$, and $\mathrm{c}$ indicate the first, second, and third experiment with that fungus at that site, respectively. 
assist with interpretation. All regression analyses were blocked on experiment within site.

\section{RESULTS}

Soil characteristics. None of the soils from commercial sites were as sandy as the campus soil, but soils from sites 4 and 5 were nearly so (Table 1). The moisture release data indicate that the tomato soils contained more fine pores than did the other soils, which had similar pore-size distributions. The bulk density in the cage was greater with the vineyard soils than with the tomato soils; the bulk density of soil surrounding cages was not assessed. Organic matter content was small in all soils (Table 1).

Site 5 was substantially more acidic than were the other sites. The $\mathrm{pH}$ determination from the DANR Laboratory used a watersaturated paste of a composite, non-heat-treated sample. Because sites 4 and 5 seemed similar in most ways and because the $\mathrm{pH}$ difference was so large, the $\mathrm{pH}$ was determined for four additional samples (collected in February, April, and May 1998) each from sites 4 and 5. A $0.01-\mathrm{M} \mathrm{CaCl}_{2}$ solution rather than water was used to make the paste; in my experience, this solution usually provides more stable but more acidic $\mathrm{pH}$ values than does water when used for sandy soils. The ranges in $\mathrm{pH}$ values in the additional samples from sites 4 and 5 were 6.3 to 6.6 and 4.2 to 4.9 , respectively. Heat treatment of one sample each from sites 4 and 5 increased the $\mathrm{pH}$ from 6.4 to 6.5 and from 4.9 to 5.0 , respectively.

M. gephyropagum. Resident $M$. gephyropagum was not detected in any of the sites. The population density of $M$. gephyropagum was seldom affected by mesh but was frequently greater in heat-treated than in non-heat-treated soil (Fig. 1, Table 2). The effect of heat was significant whether rain/irrigation was infrequent (Fig. $1 \mathrm{H}$ and $\mathrm{K}$ ) or frequent (Fig. $1 \mathrm{G}$ and I). Numbers of M. gephyropagum tended to be smaller in the cooler soils of early spring than in the warmer soils of late spring (Fig. 1, top versus bottom row). For numbers of $M$. gephyropagum and other variables, block and the interaction of mesh $\times$ soil treatment were seldom significant (Table 2) and are not discussed further.

In experiments with $M$. gephyropagum, the fungus $M$. ellipsosporum, which produces stalked, adhesive knobs, was always detected in non-heat-treated samples from site 5. It was unaffected by mesh, and its mean population density was $19 \pm 3$ propagules per gram of soil. Other resident nematode-trapping fungi occurred in all sites, but numbers were always less than five per gram of soil (data not shown).

H. rhossiliensis. Resident $H$. rhossiliensis was not detected at site 3 but was detected at sites 4 and 5. Assay nematodes with adherent conidia in cages not containing $H$. rhossiliensis pellets usually had only one or two conidia each.

Like $M$. gephyropagum, growth of $H$. rhossiliensis from pellets was largely unaffected by mesh but was often greater in heat-treated than in non-heat-treated soil (Fig. 2, Table 2). The effect of heat was significant regardless of rainfall (Fig. 2A versus B) or temperature (Fig. 2D versus F). Although the experimental design did not permit statistical comparison of sites, $H$. rhossiliensis increased to greater numbers at site 5 than at site 4 . At site 5 , in particular, large numbers of conidia ( $>10)$ adhered to most of the assay nematodes recovered from cages containing pellets. The high percentage of assay nematodes with conidia may have masked treatment effects at site 5 .

Enchytraeids. Representative enchytraeids from sites 1 to 3 were identified as Enchytraeus sp. by W. Didden. At the start of ex-
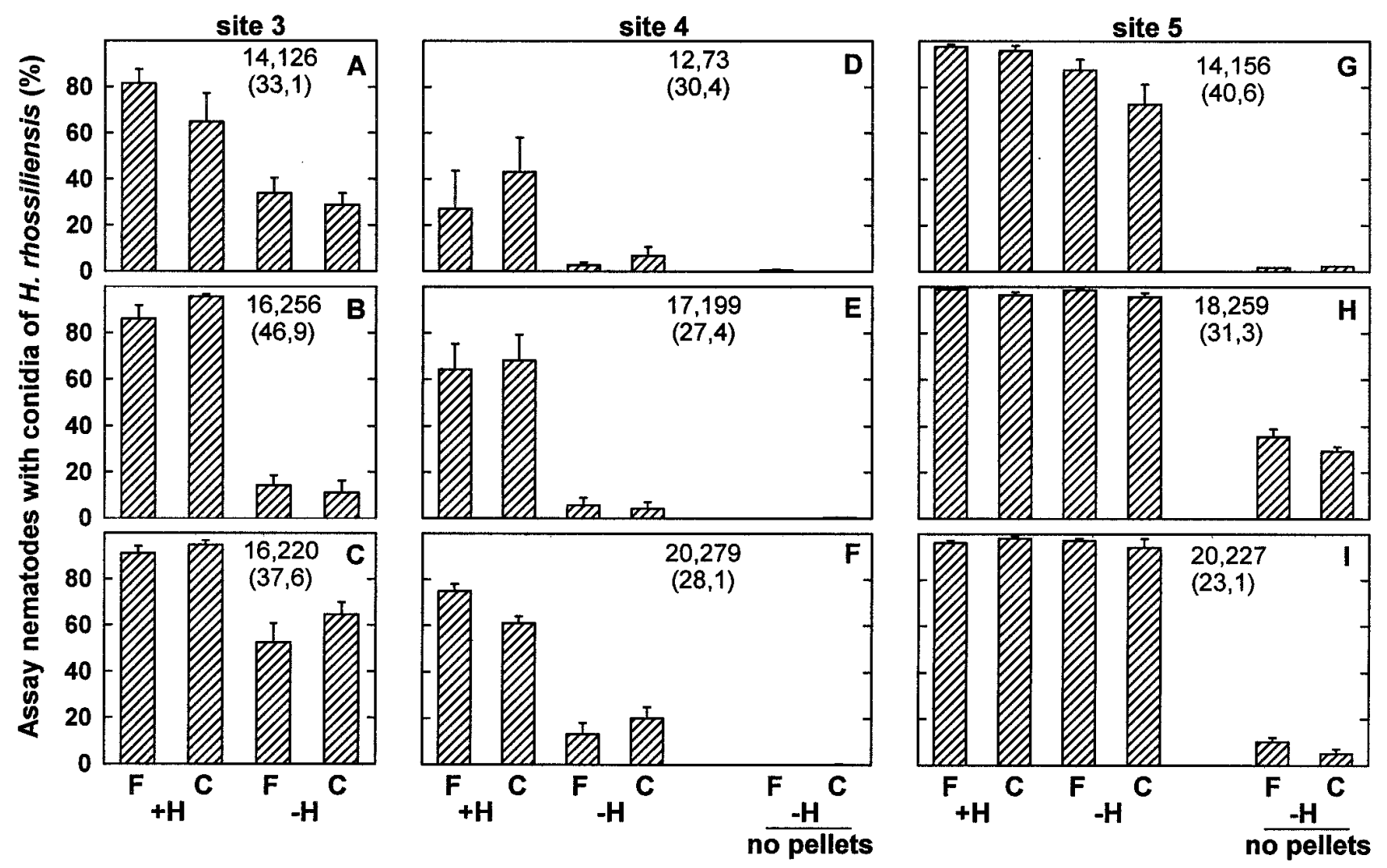

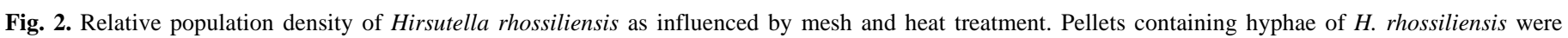

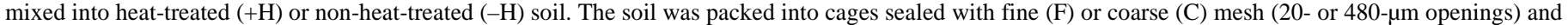

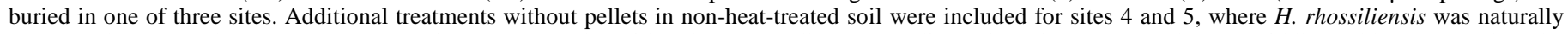

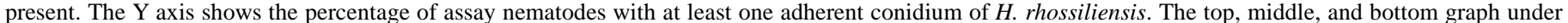

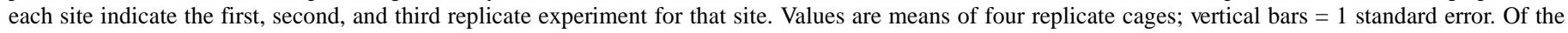

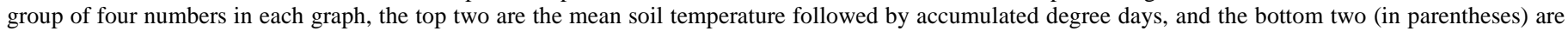
the number of days the cages were in the field followed by the number of days with rain $(>5 \mathrm{~mm})$ or irrigation. 
periments, numbers of enchytraeids in soil surrounding cages were relatively small; they never exceeded 44 per $80 \mathrm{~cm}^{3}$ of soil and exceeded 12 per $80 \mathrm{~cm}^{3}$ of soil in only two of the 21 experiments (data not shown). Enchytraeids were usually affected by mesh but never by heat treatment of soil (Fig. 3, Table 2). Fine mesh excluded enchytraeids from heat-treated soil in all but two experiments (Fig. 3Q and R) and usually suppressed enchytraeid numbers in non-heat-treated soil.

Averaged over the six experiments with $H$. rhossiliensis at sites 4 and 5 and in cages with fine and coarse mesh, enchytraeid population densities were $7 \pm 3$ times greater when pellets were added than when pellets were not added (data not shown). The other fauna also were stimulated by pellets; for example, bacterivorous nematode numbers were $4 \pm 1$ times greater in the presence than in the absence of pellets.

Nematodes, collembolans, and mites. Although statistical interactions between treatment $\times$ experiment within site were occasionally significant, the data for each site have been averaged to illustrate major trends (Figs. 4 and 5).

Nematodes were not excluded by fine mesh, and fungivorous and bacterivorous nematodes were sometimes more abundant in cages with fine mesh than in those with coarse mesh (Fig. 4, Table 2). Fungivorous nematodes (mostly Aphelenchus spp.), omnivorous nematodes (mostly dorylaimids), and bacterivorous nematodes were often more abundant in non-heat-treated than in heat-treated soil (Fig. 4, Table 2).

Collembolans and mites were often more abundant in cages with coarse mesh than in those with fine mesh but were seldom affected by heat treatment of soil (Fig. 5, Table 2). Fine mesh always excluded collembolans but not mites from heat-treated soil (Fig. 5).

Soil water. Mesh or heat treatment often affected soil water (as measured at the end of each experiment), but the effects were neither large nor consistent (Table 2). The greatest difference occurred with $M$. gephyropagum at site 1 , experiment 2 : the mean percentage of water in heat-treated soil with fine and coarse mesh and nonheat-treated soil with fine and coarse mesh was 12.6, 11.2, 12.6, and 12.2 (standard errors < 0.6), respectively. Differences among treatments were usually much less than that, even when statistically significant. Thus, with $H$. rhossiliensis (site 5, experiment 1 ), the percentage of water was (treatment order as above) 9.3, 9.1, 8.9, and 8.9 (standard errors < 0.2), respectively.

Regressions. Based on the stepwise regression statistics for sites with $M$. gephyropagum, fungivorous nematodes and enchytraeids were selected as common independent variables for multiple regression analyses (Table 3). The variable 'fungivorous nematodes' was selected because it was significant $(P<0.05)$ in four of four stepwise regressions; the exponentiated coefficient was less than 1.0 , indicating an inverse relationship, in three cases, and greater than 1.0, indicating a direct relationship, in one case. The variable 'enchytraeids' was selected because it was significant in one case and because enchytraeids were a focus of this research. In the multiple regression analyses, the coefficients for fungivorous nematodes were always significant and less than 1.0 at sites 1,2 , and 4 but greater than 1.0 at site 5 . The coefficient for enchytraeids was significant only at site 2 .

Based on stepwise regression with $H$. rhossiliensis, fungivorous and omnivorous nematodes were selected as common independent variables (Table 3). In the multiple regression analyses, the coefficient for fungivorous nematodes was significant at site 3 , and the coefficient for omnivorous nematodes was significant at sites 3 and 5 ; the significant coefficients were less than 1.0, indicating inverse relationships.

\section{DISCUSSION}

Contrary to the results of a previous study (19) and to the hypothesis of this paper, numbers of the nematophagous fungi $H$. rhossiliensis and $M$. gephyropagum did not increase when protected by

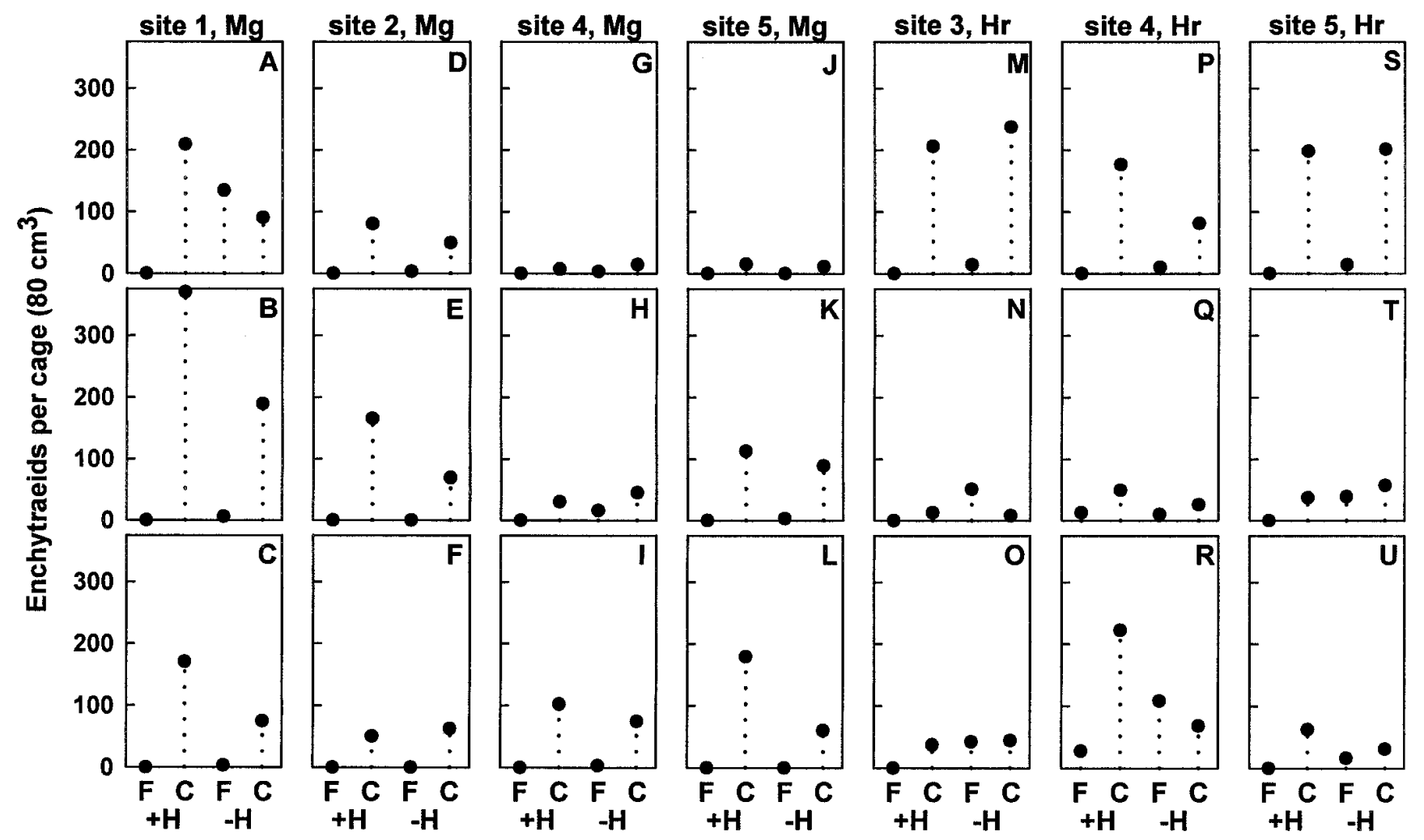

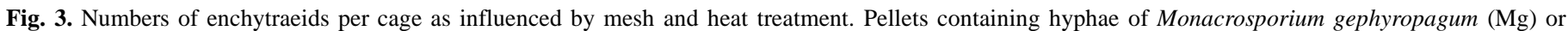

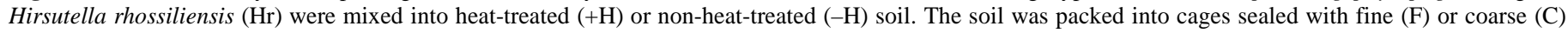

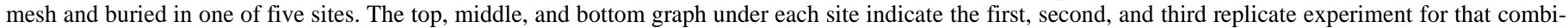
nation of fungus and site. Values are means of four replicate cages. 
fine mesh. To understand the failure of the fine mesh to enhance fungus numbers, we should first ask whether the fine mesh performed as intended. It did. In addition to suppressing collembolans and mites, fine mesh excluded enchytraeids in almost all cages with heat-treated soil and substantially reduced enchytraeid numbers in cages with non-heat-treated soil.

Although enchytraeid numbers were much greater in cages with coarse mesh than with fine mesh, numbers in cages with coarse mesh were, nevertheless, relatively small. For example, in campus plots, where the fine mesh enhanced the fungi, numbers frequently exceeded 500, and sometimes exceeded 1,500, in cages with coarse mesh (19). In contrast, numbers in the commercial fields of the current study seldom exceeded 200 and were often less than 100 per cage. Similarly, enchytraeid numbers in soil surrounding cages were greater than 120 per $80 \mathrm{~cm}^{3}$ of soil in the campus plots (19) but usually less than 12 per $80 \mathrm{~cm}^{3}$ of soil in the commercial fields of the current study. This difference in enchytraeid number could explain why fine mesh enhanced the fungi in the previous study (19) but not in the current study.

The reason for relatively small numbers of enchytraeids in the commercial fields is not clear. After the data were collected in 1997, I suspected that macroporosity in the three commercial tomato fields was insufficient to support rapid movement of enchytraeids, collembolans, and mites to the pellets. Two additional vineyard soils with high sand content and macroporosity were, therefore, included. The data from these vineyard soils, however, were largely consistent with those from the tomato fields.

Other possible explanations for the differences in data from campus versus commercial plots include differences in plot maintenance, enchytraeid species, and soil depth. The campus plots received frequent irrigation and were always planted with a host for root-knot nematode, whereas the commercial plots received less frequent irrigation and, in the case of the tomato fields, were fallow for significant times each year. The dominant enchytraeid in our campus plots was Enchytraeus crypticus, but species in the commercial fields remain unknown. Although some species clearly consume fungi, the feeding biology of enchytraeids is not well characterized (5) and other species may not consume fungi at all. Finally, the cages in the commercial fields were buried $10 \mathrm{~cm}$ deeper than were those in the campus plots, and enchytraeids, like collembolans and mites, are affected by soil depth $(6,45)$.

Pretreatment of soil with heat, rather than fine mesh, enhanced the population numbers of added fungi at all sites and over a considerable range of temperatures and moistures. This finding is consistent with the established idea that native soil is biologically buffered against introduced organisms $(1,9,37,46)$

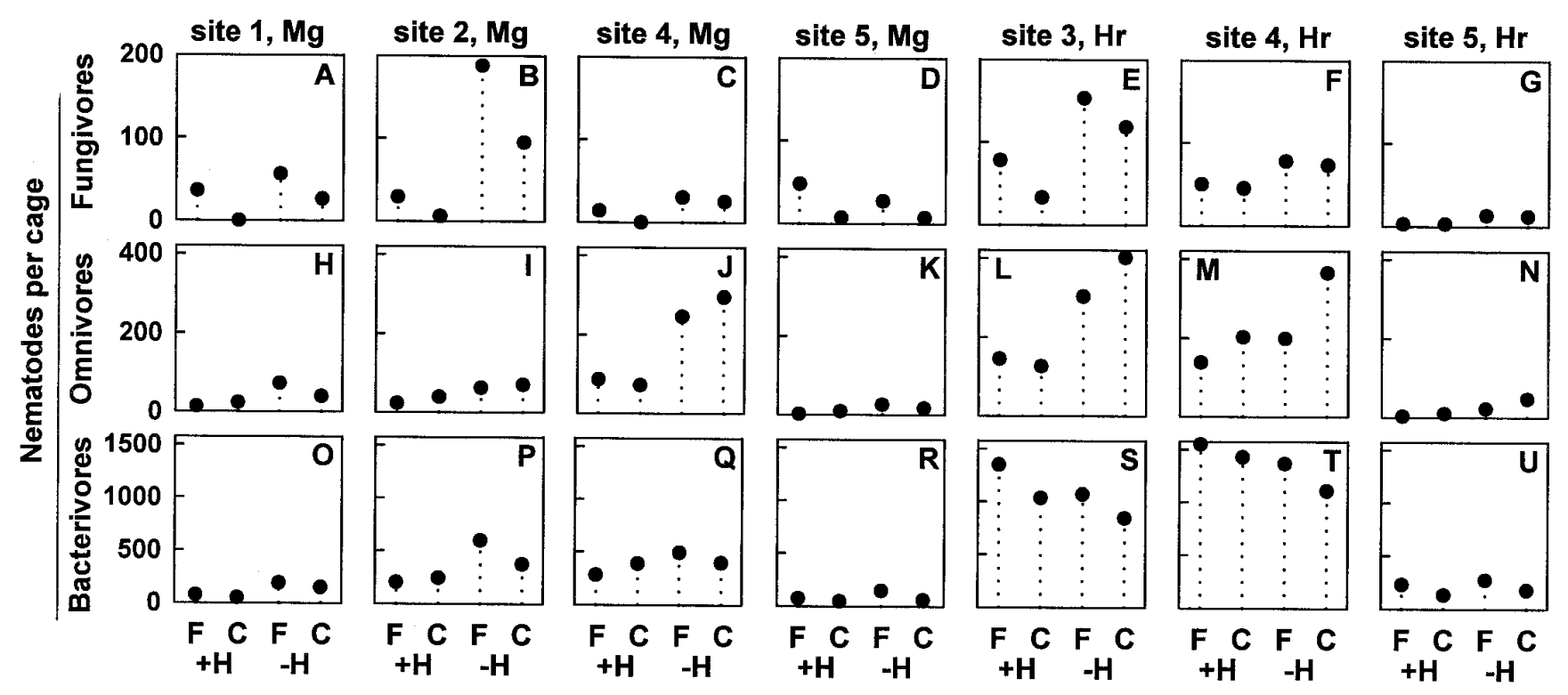

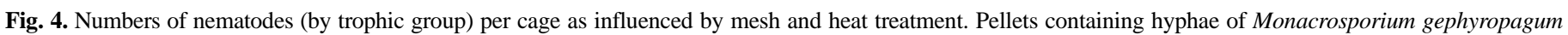

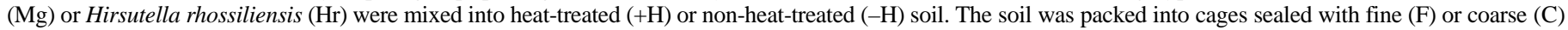

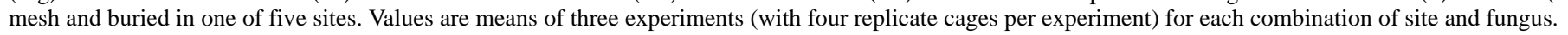
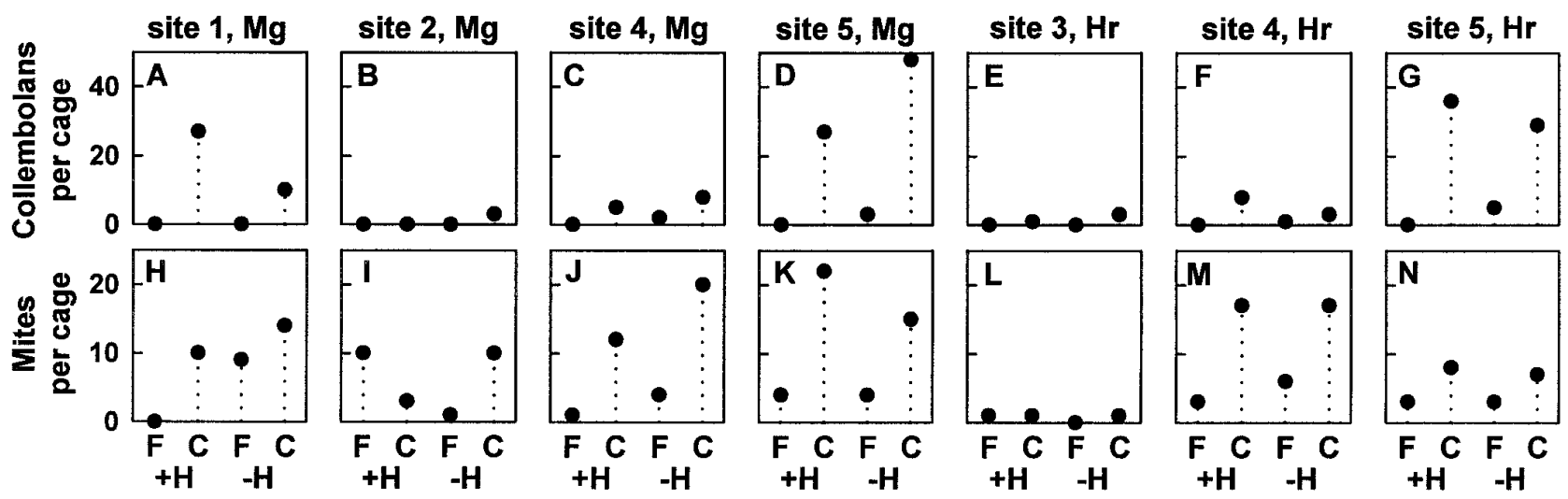

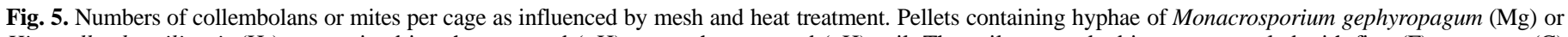

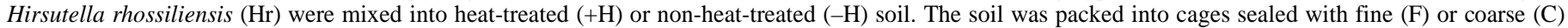
mesh and buried in one of five sites. Values are means of three experiments (with four replicate cages per experiment) for each combination of site and fungus. 
and that various biocides including heat reduce that buffering ( 7 , $10,30,31,36)$. But this generalization may not apply to all soils or fungi $(8,26)$.

Because infection of nematodes by conidia was insensitive to biotic antagonism (22), my colleagues and I initially discounted biological buffering as a problem in using $H$. rhossiliensis. We inferred that $H$. rhossiliensis had evolved to minimize competition from saprophytic microorganisms by specializing in parasitism of nematodes and that it would be insensitive to biotic antagonism when sporulating from infected nematodes. We hoped that sporulation from pellets also would be insensitive, but based on the current study, that is not the case. We now must reconsider whether sporulation from the parasitized nematode is similarly limited by biotic antagonism. If sporulation from the nematode is not limited by biotic antagonism, the pellet formulation fails to mimic the fungus-parasitized nematode in some essential way.

The biotic antagonists are apparently smaller than $20 \mu \mathrm{m}$ (the pore diameter of the fine mesh); if larger than $20 \mu \mathrm{m}$, they do not move enough to be stopped by a mesh barrier. Because the latter seems unlikely, the antagonists probably are microorganisms, protozoa, or nematodes. Data on microorganisms and protozoa were not collected, but numbers of omnivorous and especially fungivorous nematodes were negatively correlated with numbers of the nematophagous fungi in several sites. Determining whether the correlation reflects cause and effect will require additional research. In the case of fungivorous nematodes, the research will be

TABLE 3. Statistics for regressions of Monacrosporium gephyropagum and Hirsutella rhossiliensis numbers (dependent variable) on several independent variables ${ }^{y}$

\begin{tabular}{|c|c|c|c|c|c|}
\hline Fungus & Site & $R^{2}$ & Independent variable & $\begin{array}{c}\text { Exponentiated } \\
\text { coefficient }^{\mathrm{z}}\end{array}$ & $P$ \\
\hline \multicolumn{6}{|c|}{ Models fit using stepwise regression } \\
\hline \multirow[t]{7}{*}{ M. gephyropagum } & 1 & 0.48 & Mites & 0.72 & 0.02 \\
\hline & & & Fungivorous nematodes & 0.79 & 0.04 \\
\hline & 2 & 0.68 & Enchytraeids & 0.76 & $<0.01$ \\
\hline & & & Fungivorous nematodes & 0.80 & $<0.01$ \\
\hline & 4 & 0.68 & Fungivorous nematodes & 0.84 & 0.02 \\
\hline & 5 & 0.23 & Fungivorous nematodes & 1.32 & 0.01 \\
\hline & & & Omnivorous nematodes & 0.76 & 0.03 \\
\hline \multirow[t]{5}{*}{ H. rhossiliensis } & 3 & 0.56 & Omnivorous nematodes & 0.20 & $<0.01$ \\
\hline & & & Fungivorous nematodes & 0.66 & $<0.01$ \\
\hline & 4 & 0.18 & Fungivorous nematodes & 0.70 & 0.04 \\
\hline & 5 & 0.50 & Bacterivorous nematodes & 0.75 & 0.05 \\
\hline & & & Omnivorous nematodes & 0.70 & $<0.01$ \\
\hline \multicolumn{6}{|c|}{ Models fit using multiple regression } \\
\hline \multirow[t]{8}{*}{ M. gephyropagum } & 1 & 0.44 & Fungivorous nematodes & 0.77 & 0.04 \\
\hline & & & Enchytraeids & 0.88 & 0.11 \\
\hline & 2 & 0.68 & Fungivorous nematodes & 0.80 & $<0.01$ \\
\hline & & & Enchytraeids & 0.76 & $<0.01$ \\
\hline & 4 & 0.68 & Fungivorous nematodes & 0.83 & 0.01 \\
\hline & & & Enchytraeids & 1.02 & 0.78 \\
\hline & 5 & 0.16 & Fungivorous nematodes & 1.45 & $<0.01$ \\
\hline & & & Enchytraeids & 1.13 & 0.36 \\
\hline \multirow[t]{6}{*}{ H. rhossiliensis } & 3 & 0.56 & Fungivorous nematodes & 0.66 & $<0.01$ \\
\hline & & & Omnivorous nematodes & 0.20 & $<0.01$ \\
\hline & 4 & 0.22 & Fungivorous nematodes & 0.73 & 0.07 \\
\hline & & & Omnivorous nematodes & 0.64 & 0.15 \\
\hline & 5 & 0.45 & Fungivorous nematodes & 1.04 & 0.69 \\
\hline & & & Omnivorous nematodes & 0.70 & $<0.01$ \\
\hline
\end{tabular}

${ }^{\text {y }}$ H. rhossiliensis bioassay data were logit-transformed (log [number of assay nematodes with conidia +1$]$ /[number of assay nematodes without conidia +1$]$ ), and all other data were log-transformed. Natural logarithms were used. $M$. gephyropagum population densities are per gram of dry soil. Population densities for all independent variables are per cage. $n=48$ for each analysis.

${ }^{\mathrm{z}}$ Exponentiated coefficients represent the estimated multiplicative change in the dependent variable associated with a multiplicative increase of approximately 2.72 (base of the natural $\log$ ) in the concentration of the independent variable. Coefficients less than 1.0 indicate inverse relationships, and those greater than 1.0 indicate direct relationships. As the exponentiated coefficient gets further from 1.0, the degree of change in the dependent variable with a given change in the independent variable increases. interesting and difficult because fungivorous nematodes both consume and are consumed by nematode-trapping fungi $(2,34)$.

While eliminating various antagonists, heat also releases nutrients (1), and improved growth in heat-treated soil could reflect increased nutrition. This explanation seems unlikely, however, because heated soil contains large numbers of bacteria and fungi (19) that should easily win in any saprophytic competition with $H$. rhossiliensis. Yet another side effect of heat treatment would be the temporary elimination of host nematodes. If host nematodes greatly enhance the establishment of the added fungi, the fungi might do poorly in heat-treated soil. The opposite occurred. Moreover, the hyphae in the pellet contain large amounts of assimilate. This assimilate supports substantial growth even without added substrate and even when pellets are placed on plastic surfaces without soil or nematodes (44). Other limitations and potential artifacts of heat and mesh have been discussed $(19,35)$.

Statistical comparison between sites was not designed, but the greater activity of $H$. rhossiliensis in site 5 versus sites 3 and 4 should not be ignored. In particular, sites 4 and 5 seem similar in all ways except soil pH: site 4 is nearly neutral, whereas site 5 is acidic. Because the optimum $\mathrm{pH}$ for sporulation from $H$. rhossiliensisparasitized nematodes on buffered agarose was 5 (21) and because large numbers of resident $H$. rhossiliensis have been associated with acidic soils (B. A. Jaffee, unpublished data), the proliferation of $H$. rhossiliensis at site 5 makes sense. The relative success of $H$. rhossiliensis at site 5 suggests that nematophagous fungi should be added to soils or locations for which they are adapted.

In conclusion, the data do not support the hypothesis that enchytraeids interfere with our formulation of nematophagous fungi but do indicate interference by organisms smaller than $20 \mu \mathrm{m}$. Understanding which organisms interfere would, of course, be useful. It would be even more useful, however, to know whether organisms also interfere with growth of the fungi from fungus-parasitized nematodes. If not, closer study of the fungus-parasitized nematode may indicate ways to improve the formulation.

\section{ACKNOWLEDGMENTS}

I thank G. Miyao (farm advisor for Yolo County) and P. Verdegaal (farm advisor for San Joaquin County) for helping me locate fields and cooperative growers, and S. Lange, S. Meek, S. Borchard, and J. Tecklenburg for allowing me to work in their fields. I also thank L. Timm and J. Jernigan for technical help, N. Willits for statistical advice, and E. Caswell-Chen and A. Koppenhöfer for comments on an earlier version of the manuscript.

\section{LITERATURE CITED}

1. Cook, R. J., and Baker, K. F. 1983. The Nature and Practice of Biological Control of Plant Pathogens. The American Phytopathological Society, St. Paul, MN.

2. Cooke, R. C., and Pramer, D. 1968. Interactions of Aphelenchus avenae and some nematode-trapping fungi in dual culture. Phytopathology 58: 659-661.

3. Curl, E. A., and Lartey, R. T. 1996. Role of soil fauna in biological control of Rhizoctonia. Pages 495-506 in: Rhizoctonia Species: Taxonomy, Molecular Biology, Ecology, Pathology and Disease Control. B. Sneh, S. Jabaji-Hare, S. Neate, and G. Dijst, eds. Kluwer Academic, Dordrecht, the Netherlands.

4. de Leij, F. A. A. M., Kerry, B. R., and Dennehy, J. A. 1993. Verticillium chlamydosporium as a biological control agent for Meloidogyne incognita and M. hapla in pot and micro-plot tests. Nematologica 39:115-126.

5. Didden, W. A. M. 1993. Ecology of terrestrial Enchytraeidae. Pedobiologia 37:2-29.

6. Didden, W. A. M., and de Fluiter, R. 1998. Dynamics and stratification of Enchytraeidae in the organic layer of a Scots pine forest. Biol. Fertil. Soils 26:305-312.

7. Eren, J., and Pramer, D. 1978. Growth and activity of the nematode-trapping fungus Arthrobotrys conoides in soil. Pages 121-127 in: Microbial Ecology. M. W. Loutit and J. A. R. Miles, eds. Springer-Verlag, Berlin.

8. Fravel, D. R., Stosz, S. K., and Larkin, R. P. 1996. Effect of temperature, soil type, and matric potential on proliferation and survival of Fusarium oxysporum f. sp. erythroxyli from Erythroxylum coca. Phytopathology 
$86: 236-240$.

9. Garrett, S. D. 1956. Biology of Root-Infecting Fungi. Cambridge University Press, New York.

10. Giuma, A. Y., and Cooke, R. C. 1974. Potential of Nematoctonus conidia for biological control of soil-borne phytonematodes. Soil Biol. Biochem. 6:217-220.

11. Gottwald, T. R., and Tedders, W. L. 1984. Colonization, transmission, and longevity of Beauveria bassiana and Metarhizium anisopliae (Deuteromycotina: Hyphomycetes) on pecan weevil larvae (Coleoptera: Curculionidae) in the soil. Environ. Entomol. 13:557-560.

12. Gracia-Garza, J. A., Reeleder, R. D., and Paulitz, T. C. 1997. Degradation of sclerotia of Sclerotinia sclerotiorum by fungus gnats (Bradysia coprophila) and the biocontrol fungi Trichoderma spp. Soil Biol. Biochem. 29:123-129.

13. Hajek, A. E. 1997. Entomophaga maimaiga reproductive output is determined by the spore type initiating an infection. Mycol. Res. 101:971974.

14. Jaffee, B. A., and Muldoon, A. E. 1995. Susceptibility of root-knot and cyst nematodes to the nematode-trapping fungi Monacrosporium ellipsosporum and M. cionopagum. Soil Biol. Biochem. 27:1083-1090.

15. Jaffee, B. A., and Muldoon, A. E. 1995. Numerical responses of the nematophagous fungi Hirsutella rhossiliensis, Monacrosporium cionopagum, and M. ellipsosporum. Mycologia 87:643-650.

16. Jaffee, B. A., and Muldoon, A. E. 1997. Suppression of the root-knot nematode Meloidogyne javanica by alginate pellets containing the nematophagous fungi Hirsutella rhossiliensis, Monacrosporium cionopagum and M. ellipsosporum. Biocontrol Sci. Technol. 7:203-217.

17. Jaffee, B. A., Muldoon, A. E., and Didden, W. A. M. 1997. Enchytraeids and nematophagous fungi in soil microcosms. Biol. Fertil. Soils 25:382-388.

18. Jaffee, B. A., Muldoon, A. E., and Tedford, E. C. 1992. Trap production by nematophagous fungi growing from parasitized nematodes. Phytopathology 82:615-620.

19. Jaffee, B. A., Santos, P. F., and Muldoon, A. E. 1997. Suppression of nematophagous fungi by enchytraeid worms: A field exclosure experiment. Oecologia 112:412-423.

20. Jaffee, B. A., Strong, D. R., and Muldoon, A. E. 1996. Nematode-trapping fungi of a natural shrubland: Tests for food chain involvement. Mycologia 88:554-564.

21. Jaffee, B. A., and Zehr, E. I. 1983. Sporulation of the fungus Hirsutella rhossiliensis from the nematode Criconemella xenoplax. Plant Dis. 67: 1265-1267.

22. Jaffee, B. A., and Zehr, E. I. 1985. Parasitic and saprophytic abilities of the nematode-attacking fungus Hirsutella rhossiliensis. J. Nematol. 17: 341-345.

23. Jager, G., and Velvis, H. 1996. Biological destruction of conidia of Verticillium biguttatum. Eur. J. Plant Pathol. 102:623-633.

24. Jansson, H.-B., Jeyaprakash, A., and Zuckerman, B. M. 1985. Control of root-knot nematodes on tomato by the endoparasitic fungus Meria coniospora. J. Nematol. 17:327-329.

25. Jenkins, W. R. 1964. A rapid centrifugal-flotation technique for separating nematodes from soil. Plant Dis. Rep. 48:692.

26. Kerry, B. R., Simon, A., and Rovira, A. D. 1984. Observations on the introduction of Verticillium chlamydosporium and other parasitic fungi into soil for control of the cereal cyst-nematode Heterodera avenae. Ann. Appl. Biol. 105:509-516.

27. Klee, A. 1993. A computer program for the determination of most probable number and its confidence limits. J. Microbiol. Methods 18:91-98.

28. Lackey, B. A., Muldoon, A. E., and Jaffee, B. A. 1993. Alginate pellet formulation of Hirsutella rhossiliensis for biological control of plant- parasitic nematodes. Biol. Control 3:155-160.

29. Liddell, C. M. 1992. Measurement and control of soil temperature and water potential. Pages 187-203 in: Methods for Research on Soilborne Phytopathogenic Fungi. L. L. Singleton, J. D. Mihail, and C. M. Rush, eds. The American Phytopathological Society, St. Paul, MN.

30. Mankau, R. 1962. Soil fungistasis and nematophagous fungi. Phytopathology 52:611-615.

31. Marois, J. J., and Mitchell, D. J. 1981. Effects of fungal communities on the pathogenic and saprophytic activities of Fusarium oxysporum f. sp. radicis-lycospersici. Phytopathology 71:1251-1256.

32. McInnis, T. M., and Jaffee, B. A. 1989. An assay for Hirsutella rhossiliensis spores and the importance of phialides for nematode inoculation. J. Nematol. 21:229-234.

33. Meyer, S. L. F., Johnson, G., Dimock, M., Fahey, J. W., and Huettel, R. N. 1997. Field efficacy of Verticillium lecanii, sex pheromone, and pheromone analogs as potential management agents for soybean cyst nematode. J. Nematol. 29:282-288.

34. Monoson, H. L. 1968. Trapping effectiveness of five species of nematophagous fungi cultured with mycophagous nematodes. Mycologia 60: 788-801.

35. Nieminen, J. K., and Setälä, H. 1998. Enclosing decomposer food web: Implications for community structure and function. Biol. Fertil. Soils 26: 50-57.

36. Pereira, R. M., Alves, S. B., and Stimac, J. L. 1993. Growth of Beauveria bassiana in fire ant nest soil with amendments. J. Invertebr. Pathol. 62:9-14.

37. Rosenheim, J. A. 1998. Higher-order predators and the regulation of insect herbivore populations. Annu. Rev. Entomol. 43:421-447.

38. Schmelz, R. M. 1996. Species separation and identification in the Enchytraeidae (Oligochaeta, Annelida): Combining morphology with general protein data. Hydrobiologia 334:31-36.

39. Scholte, K., and Lootsma, M. 1998. Effect of farmyard manure and green manure crops on populations of mycophagous soil fauna and Rhizoctonia stem canker of potato. Pedobiologia 42:223-231.

40. Stephens, P. M., and Davoren, C. W. 1997. Influence of the earthworms Aporrectodea trapezoides and A. rosea on the disease severity of Rhizoctonia solani on subterranean clover and ryegrass. Soil Biol. Biochem. 29:511-516.

41. Stirling, G. R. 1991. Biological Control of Plant Parasitic Nematodes. CAB International, Wallingford, Oxon, United Kingdom.

42. Stirling, G. R., and Smith, L. J. 1998. Field tests of formulated products containing either Verticillium chlamydosporium or Arthrobotrys dactyloides for biological control of root-knot nematodes. Biol. Control 11: 231-239.

43. Tedford, E. C., Jaffee, B. A., and Muldoon, A. E. 1992. Effect of soil moisture and texture on transmission of the nematophagous fungus Hirsutella rhossiliensis to cyst and root-knot nematodes. Phytopathology 82:1002-1007.

44. Tedford, E. C., Jaffee, B. A., and Muldoon, A. E. 1995. Suppression of the nematode Heterodera schachtii by the fungus Hirsutella rhossiliensis as affected by fungus population density and nematode movement. Phytopathology 85:613-617.

45. van Vliet, P. C. J., Coleman, D. C., and Hendrix, P. F. 1997. Population dynamics of Enchytraeidae (Oligochaeta) in different agricultural systems. Biol. Fertil. Soils 25:123-129.

46. Wilhelm, S. 1965. Analysis of biological balance in natural soil. Pages 509-518 in: Ecology of Soil-Borne Plant Pathogens-Prelude to Biological Control. K. F. Baker and W. C. Snyder, eds. University of California Press, Berkeley.

\section{Erratum}

\section{Vol. 89, No. 5, 1999}

In the manuscript entitled "Enchytraeids and Nematophagous Fungi in Tomato Fields and Vineyards" by B. A. Jaffee (Phytopathology 89:398-406), the first line of the Materials and Methods section contains an incorrect isolate number for M. gephyropagum. The correct number is ARSEF 3349, which is equivalent to ATCC 96959. 